\title{
A new luminescent Ru(terpy) complex incorporating a 1,2,4-triazole based $\sigma$-donor ligand
}

\author{
Marco Duati, Stefano Fanni, Johannes G. Vos*. \\ Inorganic Chemistry Research Centre, School of Chemical Sciences, Dublin City University, Dublin 9, \\ Ireland.
}

\begin{abstract}
The mononuclear compound $[\mathrm{Ru}($ terpy $) \mathrm{L}]$, where $\mathrm{H}_{2} \mathrm{~L}$ is 2,6-bis(1,2,4-triazol-3yl)pyridine, shows an emission lifetime of $65 \mathrm{~ns}$, about 300 times longer than that observed for the parent $\left[\mathrm{Ru}(\text { terpy })_{3}\right]^{2+}$ complex.
\end{abstract}

Keywords: Ruthenium; terpyridine; emission lifetime; 1,2,4-triazole.

\section{Introduction}

Ruthenium polypyridine complexes are widely used as photosensitisers in covalently linked multicomponent systems. Their photophysical properties make them ideal candidates as building blocks for the design of supramolecular species performing complex light induced functions [1].

The polypyridyl ligands employed are mainly derivatives or analogues of the bidentate 2,2'-bipyridine or derivatives or analogues of the tridentate 2,6,2',2'-terpyridine (terpy) [1-3]. Tridentate terpyridine-type ligands are ideal from a geometrical point of view as they can form achiral complexes for which the $C_{2 v}$ symmetry is not affected by substitution in the 4 position of the terpy ligands. Furthermore, the "rod-like" geometry of these complexes offers the best spatial arrangement for the synthesis of triads or molecular wires. However, the very short excited-state lifetime and weak luminescence intensity of $\left[\mathrm{Ru}(\text { terpy })_{2}\right]^{2+}$ at room temperature, represent a severe 
limitation to the application of this complex as photosensitiser. Improvement of the photophysical properties of terpy-based $\mathrm{Ru}(\mathrm{II})$ complexes is therefore currently the object of intensive studies [4-8]. As a contribution to these studies, we wish to report the new $\left[\mathrm{RuL}\left(\right.\right.$ terpy)] mononuclear complex, where $\mathrm{H}_{2} \mathrm{~L}$ is 2,6-bis(1,2,4-triazol-3yl)pyridine, which exhibits a remarkable 300-fold increase of the emission lifetime when compared with the parent compound $\left[\mathrm{Ru}(\text { terpy })_{2}\right]^{2+}$;

\section{Experimental}

2,6-bis(1,2,4-triazol-3-yl)pyridine was synthesised, in high yield, following the literature pathway $[9,10]$ for similar compounds.

The $\mathrm{Ru}$ (terpy) complex was obtained by heating $\left[\mathrm{Ru}(\right.$ terpy) $] \mathrm{Cl}_{3}$ and a stoichiometric amount of the ligand $\mathrm{H}_{2} \mathrm{~L}$ in water containing a slight molar excess of $\mathrm{NaOH}$ and few drops of N-ethylmorpholine. The reaction mixture was refluxed for two hours; the dark green solution was concentrated, acidified to $\mathrm{pH} 3$ with $\mathrm{HCl}$ and an excess of $\mathrm{NH}_{4} \mathrm{PF}_{6}$ was added. Purification by column chromatography on alumina (acetonitrile/methanol 50:50) gave a 30\% yield.

In agreement with literature [11,12], three different isomers were found [Scheme 1]. Isomers A ( $10 \%$ )and B ( $60 \%$ ) were eluted from a neutral alumina column using acetonitrile followed by the elution of the isomer $\mathrm{C}$ ( $30 \%$ ) using methanol. The identification of the three isomers is based on the chemical shift of the triazole proton in the NMR

Since isomer $\mathrm{C}$ is most easily purified all further studies were carried out using this species, both A and B yield however very similar results. Elemental analysis suggests that a mixture of monoprotonated /deprotonated (80:20) isomers is 
formed after recrystallization of $\mathrm{C}$ from acetone/water. $[\mathrm{Ru}($ terpy $)(\mathrm{HL})]\left[\mathrm{PF}_{6}\right]$ : [Ru(terpy)(L)], (80:20); Elem. Anal. calcd. C 43.52, H 2.56, N 21.15. Found C 43.7 H 2.60 N 21.03. ${ }^{1} \mathrm{H}$ NMR. $\delta_{\mathrm{H}}\left(\mathrm{CD}_{3} \mathrm{OD}, \mathrm{NaOD}\right) 8.6(2 \mathrm{H}, \mathrm{q}), 8.4(2 \mathrm{H}, \mathrm{q}), 8.2(\mathrm{H}, \mathrm{m})$, 8.1(3H, m), $7.73(2 \mathrm{H}, \mathrm{t}), 7.6(\mathrm{H}, \mathrm{d}), 7.25(2 \mathrm{H}, \mathrm{t}$ of d), $7.06(2 \mathrm{H}, \mathrm{m}), 6.98(\mathrm{H}, \mathrm{d})$. To ensure full deprotonation of the complex all measurements reported in this communication were carried out in basic media.

\section{Results and discussion}

The UV-Vis absorption spectrum of the complex $[\mathrm{Ru}($ terpy)L], isomer $\mathrm{C}$, in basic ethanol shows an intense metal-to-ligand-charge-transfer (MLCT) band at $480 \mathrm{~nm}$ (Fig.1a), with a molar extinction coefficient of $7900 \mathrm{M}^{-1} \mathrm{~cm}^{-1}$. The bands at 275, 309 and 380 are assigned to the intra ligand $\pi-\pi^{*}$ transition of the ligands. The small but distinct shoulders at $626,579 \mathrm{~nm}$ have not yet been assigned.

When excited within the MLCT absorption band at $298 \mathrm{~K}$, in a basic ethanol solution, the complex exhibits a strong emission with a single band centred at $700 \mathrm{~nm}$ (Fig.1b) and a lifetime of $65( \pm 3)$ ns. Protonation of the triazole rings results in a total quenching of the emission. Based on results reported in the literature for other ruthenium polypyridyl complexes containing 1,2,4-triazole containing ligands this emission is more than likely terpy based and the bistriazolepyridine ligand acts as a spectator ligand.[13] The emission lifetime measured for this compound represents an increase by 2 order of magnitude with respect to $\left[\mathrm{Ru}(\text { terpy })_{2}\right]^{2+}(\mathrm{Tab} .1)$. It is therefore clear that the use of the triazolato ligand dramatically extends the lifetime of the ${ }^{3} \mathrm{MLCT}$ excited state of the $\mathrm{Ru}(\mathrm{II})$ (terpy) complex. This is likely to originate from the raising of the ${ }^{3} \mathrm{MC}$ states following the replacement of the weak field terpyridine 
ligand by a strong $\sigma$-donor ligand. The absorption and emission spectra show also interesting solvatochromic properties (See Table 2), similar to these observed for $\left[\mathrm{Ru}(\right.$ terpy $\left.) \mathrm{CN}_{3}\right][8]$. This solvent dependence may be used to further manipulate the photophysical properties of the compound.

\section{Concluding remarks.}

This communication describes an alternative strategy to extend the lifetime of the triplet state in terpy-type ruthenium complexes. Usually, delocalisation of the emitting state is used to increase the lifetime of terpy based excited states [4-7]. In our approach we have raised the deactivating ${ }^{3} \mathrm{MC}$ state instead. To the best of our knowledge there is one one other compound, namely $\left[\mathrm{Ru}\left(\right.\right.$ terpy) $\left.\mathrm{CN}_{3}\right]$, where a similar approach has been taken [8]. With the ligand introduced in this contribution an increased stability is expected for the terpy complex, since monodentate cyano ligands tend to be more labile. In addition, the well-defined synthetic pathways that exist for pyridyltriazole compounds $[10,11]$ enable many modifications for these ligands. This should facilitate the synthesis of dinuclear complexes with bridging triazole ligands. Finally, the combination of this approach with thiophene [7] or alkyne [6] containing terpy ligands is expected to yield multinuclear systems with even longer emission lifetimes, which could find applications components as photosensitisers in rod-like molecular assemblies.

Acknowledgement. The authors wish to thank the EC TMR Programme (Contracts CT96-0031 and CT96-0076) for financial support. 


\section{Footnotes}

* Corresponding author, Tel.353-1-7045307, Fax. 353-1-7045503, e-mail han.vos@dcu.ie 


\section{References}

[1] V. Balzani, F. Scandola, Supramolecolar Photochemistry, Ellis Horwood: Chichester, 1991, England.

[2] V. Balzani, A. Juris, M. Venturi, S. Campagna, S. Serroni, Chem. Rev., 96 (1996) 759.

[3] A. Harriman, R. Ziessel, Coord. Chem. Rev., 171 (1998) 331.

[4] F.Barigelletti, L. Flamigni, V. Balzani, J-P. Colin, J-P Savage, A. Sour, E.C. Constable, A.M.W. Cargill Thompson, J.Am.Chem.Soc., 116 (1994) 7692.

[5] M. Maestri, N. Armaroli, V. Balzani, E.C. Constable, A.M.W. Cargill Thompson, Inorg. Chem. 34 (1995) 2759.

[6] V. Grosshenny, A. Harriman, R. Ziessel, Angew. Chem., Int. Ed. Engl. 33 (1995) 1100

[7] E.C. Constable, C.E. Housecroft, E.R. Schofield, S. Encinas, N. Armaroli, F. Barigelletti, L. Flamigni, E. Figgemeier, J.G. Vos. Chem. Commun, (1999), 869

[8] M.T. Indelli, C.A. Bignozzi, F. Scandola, J-P. Colin, Inorg. Chem., 46 (1998) 6084.

[9] R. Hage, J. G. Haasnoot, J. Reedijk, R. Wang, J. G. Vos, Inorg. Chem. 30 (1991) 3263.

[10] K. H. Suyiyarto, D. C. Craig, A. D. Rae, H. A. Goodwin, Aust. J. Chem., 46 (1993)1269.

[11] H. P. Hughes, J. G. Vos, Inorg. Chem., 34 (1995) 4001.

[12] M. G. B. Drew, M. J. Hudson, P. B. Ivenson, C. Madic and M. L. Rusel, Dalton Trans., (1999) 2433. 
[13] H.P. Hughes, D. Martin, S. Bell, J.J. McGarvey and J.G. Vos. Inorg. Chem., 32, (1993), 4402 


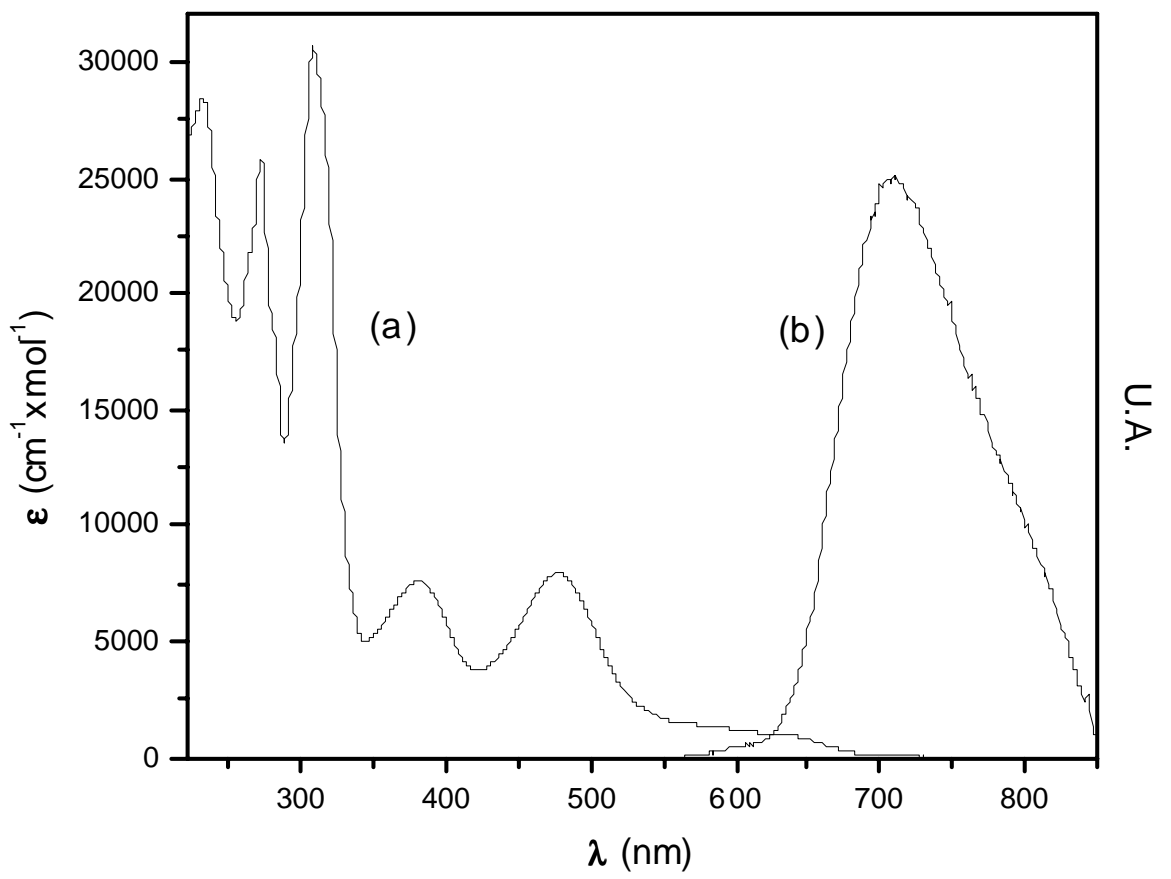

Figure Caption

Fig. 1. Absorption (a) and emission (b) spectra of the $[\mathrm{Ru}(\operatorname{terpy})(\mathrm{L})]$ in basic ethanol solution: excitation was at $474 \mathrm{~nm}$. 


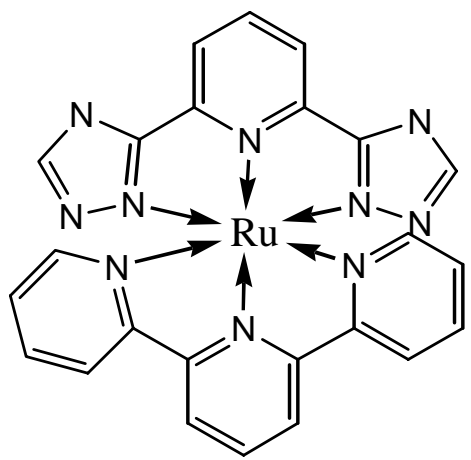

Isomer A

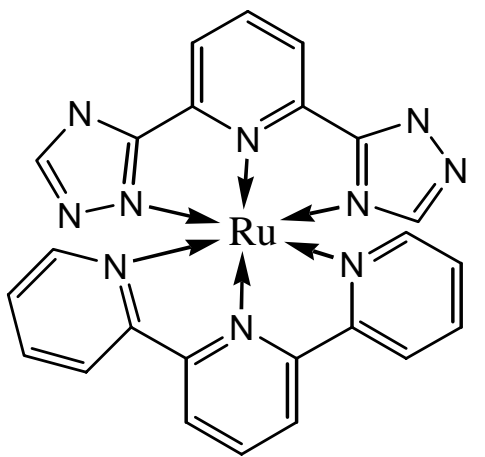

Isomer B

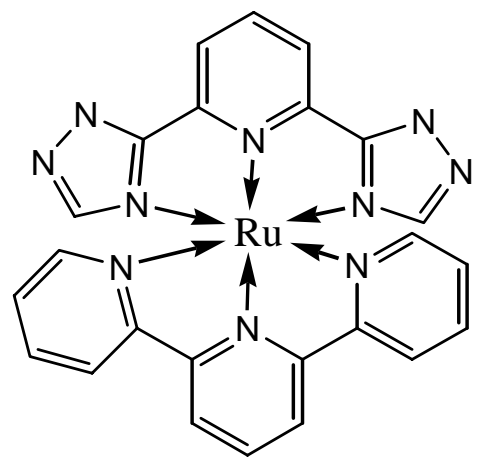

Isomer C

Scheme 1. Possible coordination isomers for [Ru(terpy)L] 
Table 1. Electronic properties ${ }^{\mathrm{a}}$

$\frac{\text { Absorption }}{\lambda_{\max } / \mathrm{nm}\left(\varepsilon \times 10^{-4} / \mathrm{M}^{-1} \mathrm{~cm}^{-1}\right)}$

$\left[\operatorname{Ru}(\text { terpy })_{2}\right]^{2+b, c}$

$[\operatorname{Ru}(\operatorname{terpy})(\mathrm{L})]^{\mathrm{d}}$
474 (10.4)

480 (7.9)
Emission

$\lambda_{\max } / \mathrm{nm} \quad \tau / \mathrm{ns}$

629

0.25

701

${ }^{a}$ Room temperature, de-aerated solution. ${ }^{\mathrm{b}}$ Refs.[8] ${ }^{\mathrm{c}}$ Acetonitrile. ${ }^{\mathrm{d}}$ Ethanol. 
Table 2. Absorption and emission properties of $[\mathrm{Ru}($ terpy) $\mathrm{L}]$ in different solvents.

Solvent (acceptor $n .^{\circ}$ )

\begin{tabular}{ccccccc}
\hline $\mathrm{H}_{2} \mathrm{O}$ & $\mathrm{MeOH}$ & $\begin{array}{c}\mathrm{EtOH} \\
(58.4)^{\mathrm{a}}\end{array}$ & $\begin{array}{c}\mathrm{CH}_{3} \mathrm{CN} \\
(41.3)\end{array}$ & $\begin{array}{c}\text { DMSO } \\
(19.3)\end{array}$ & $\begin{array}{c}\text { DMF } \\
(16.0)\end{array}$ & $\begin{array}{c}\left(\mathrm{CH}_{3}\right)_{2} \mathrm{CO} \\
(12.5)\end{array}$ \\
472 & 473.5 & 480.5 & 488 & 494 & 495 & 493 \\
692 & 693.7 & 700.9 & 740 & 741.8 & 752.3 & 734.8 \\
$663^{\mathrm{c}, \mathrm{f}}$ & & & & & & \\
\end{tabular}

${ }^{\mathrm{a}}$ Acceptor numbers were taken from Ref.[12]. ${ }^{\mathrm{b}}$ Low-energy band. ${ }^{\mathrm{c}} 9 \mathrm{M} \mathrm{LiCl}$ glass. ${ }^{\mathrm{d}}$ EtOH:MeOH (4:1) glass. ${ }^{\mathrm{e}} \mathrm{DMF}: \mathrm{CH}_{2} \mathrm{CL} 2 \mathrm{glass}$. ${ }^{\mathrm{f}}$ High energy band. 